\title{
Operación y movilización. Formas de acción colectiva pre elíticas en la Falange Nacional chilena (1935-1957) ${ }^{1}$
}

\author{
Jorge Vergara Vidal \\ Universidad Alberto Hurtado, Santiago, Chile. Email: jvergaravidal@gmail.com
}

Resumen: El presente texto desarrolla el concepto de operación como una forma específica de acción colectiva, se la considera como una movilización organizada de recursos acotados a objetivos y tiempos determinados. En el análisis de la Falange Nacional chilena es posible distinguir, entre los periodos temprano y tardío de su vida como organización, la manera como van funcionando y produciendo efectos, por lo menos dos tipos de operaciones, caracterizadas una como doctrinaria y la otra como pragmática. Los principales efectos de la performance de estos tipos se ubican en la concepción e implementación del modelo orgánico del partido y la figura vincular del agente político o adscriptor asociado a dicho modelo.

Palabras clave: Acción colectiva, operación política, movilización, partidos políticos, Falange Nacional

\section{Operation and mobilization. Pre elitical forms of collective action in chilean 'Falange Nacional' (1935-1957)}

Abstract: The following lines expose the concept of operation as a specific type of collective action, that means an organized mobilization of resources bounded in target and times. In chilean 'Falange Nacional' it is possible to distinguish, between its early and late periods as organization, the way they function and produce effects, in at least two types of operations, one characterized as doctrinaire and the other as pragmatic . The main effects of the performance of these types, are located in the conception and action of the organic model of party and in the figure of partisan member associated with that model.

Key words: Collective action, political operation, mobilization, political parties, Falange Nacional.

\section{Operação e mobilização. Pré-formas elitical de ação coletiva no Chile Falange Nacional (1935-1957)}

Resumo: As linhas a seguir expor o conceito de operação como um tipo específico de ação coletiva, que significa uma mobilização organizada de recursos limitados em alvo e os tempos. Em Falange Nacional chileno é posible distinguir, entre os períodos iniciais e finais, como operam e têm efeito, pelo menos dois tipos de operações, que se caracterizou como doutrinário e outro como pragmático. Os 
efectos principais do desempenho destes tipos estão localizados no modelo orgânico de partido e na figura do membro partidário associado com esse modelo.

Palavras-chave: ação coletiva, operação política, a mobilização, os partidos políticos, Falange Nacional.

$* * *$

\section{Introducción}

El problema del poder de minorías, dentro de las organizaciones políticas, fue tempranamente considerado por la sociología como un fenómeno asociado al modelo representativo que imperaba en los partidos analizados por Mosca (1896), Pareto (1980), Weber (1922) y Michels (1911). La articulación de estas minorías como élites eran vistas como efecto tanto del carácter masivo de las organizaciones como de la necesidad de una “conducción experta” a la cabeza de ellas (Ibid.), y en este sentido su articulación evidenciaba una especialización de la actividad política, no del todo bien recibida.

Para Ostrogorsky (1903), en cambio, la conformación de pequeños grupos operativos era motivada por la simple divergencia de intereses en la acción política. A diferencia de los autores posteriores, Ostrogorsky no apela a que la acción de grupos pequeños en un contexto político devenga necesariamente en un cierre no competitivo (Mosca, Pareto) o en una convergencia de expertos o profesionales políticos (Michels); más bien ve en ello la forma de articulación de grupos de acción organizados en pos de sus intereses, maquinarias que se ponen en función a la hora de la conquista electoral, interna y/o externa. Estos grupos, que organizan capacidades operativas no equivalen, necesariamente, a élites pero sin duda colaboran con el proceso de conducción política. Esta figura, de grupos con capacidad de control de recursos, pero sin la implicancia automática del cierre elítico, es retomada por Sartori en la figura de los "grupos controladores" (Sartori, 1988: 182), especificando así que la acción racional de los grupos dentro de los partidos podían acotarse al manejo de recursos incidentes y no exclusivamente a la conquista y ejercicio del poder.

En realidad, lo que detecta Ostrogorsky son las configuraciones de acción colectivas anteriores a los cierres elíticos que describen Mosca y Michels, principalmente. Que esto sea corroborado por Sartori, implica que es un proceso detectable en distintas épocas, lo cual no es menor pues reafirma la noción de que los procesos elíticos son organizados y desorganizados constantemente. Vale decir, nunca hay una captura definitiva de la élite respecto del campo político o del campo de lo público; en el mismo sentido, nunca es definitiva la primacía de un recurso (el conocimiento técnico, por ejemplo) sobre otros.

Lo anterior nos permite dirigir la vista hacia ese momento en que la acción colectiva no tiene la marca de la configuración elítica, que aún no ha asumido los argumentos de la "conducción experta”, contingente, perma- 
neciendo contenciosa. Ese momento organizacional, donde la acción colectiva de los individuos se encuentra produciendo y movilizando sus recursos en pos de objetivos definidos es lo que se ha denominado como operación.

El presente texto pretende desarrollar el concepto de operación como una forma específica de acción colectiva (Olson, 1992; Tarrow, 2004: 3350). Para esto se la ha definido, provisoriamente, como una forma de movilización colectiva y organizada de recursos acotados a objetivos y tiempos determinados. Lo central en esto es explicitar dos consideraciones. La primera es la diferencia de la operación respecto de otros tipos de acciones colectivas, como los movimientos y los partidos. La segunda se refiere a que, al estar determinada su formación por la emergencia de intereses de grupos e individuos acotados, es posible apreciar fenómenos como competencia y colaboración entre diferentes operaciones según sea la naturaleza de sus objetivos. Esto corresponde a lo que se ha podido apreciar en el caso de la organización política Falange Nacional (1935-1957), partido antecedente de la actual Democracia Cristiana chilena, cuyas conclusiones se exponen en esta líneas.

Sostiene Olson (1992) que el problema de la acción colectiva tiene un cariz agregativo en el sentido de su mecánica, pero no de su finalidad. Puede sumar acciones, recursos y grupos de participantes, pero no fines u objetivos. Tarrow (2004), coincidentemente, señala que la movilización de recursos es un elemento central para definir la forma orgánica que asume la acción colectiva, toda vez que los fines y objetivos de esta se constituyen como una constante en un marco racional. De esta manera es posible considerar que es la forma de movilización de los recursos en pos de objetivo, lo que permite distinguir entre tipos de acciones colectivas. La capacidad de acceder a recursos permite la efectividad de este tipo de acciones, pero ello no implica, masividad, representación o que la acción tienda al bien común en un determinado contexto. Si se sigue un principio de optimización de beneficios, más que de costos, como en la corrección de Hirschman (1982: 82-91) a Olson, el tamaño de los grupos de acción colectiva tenderían a reducirse, que es lo que Olson postula en su teoría de los “grupos pequeños” (1992: 32 ss.). El que estos grupos funcionen con efectividad dentro de los grupos mayores, pudiendo incluso competir entre sí, por lo menos en el campo político es similar a lo plateado por Ostrogorsky respecto al funcionamiento de las “máquinas políticas” (1912: 74-75). La noción de operación, que se utiliza en el texto, busca discutir y especificar esta idea de formas orgánicas menores a los movimientos y partidos, que funcionan en pos de intereses colectivos pero no comunes.

Siendo una operación un mecanismo activado en pos de logro de objetivos, se debe considerar que sus parámetros de éxito (corroboración de la acción) están definidos dentro de su diseño. En este sentido una operación cumple su función positivamente, beneficiando la posición de sus gestores, o la cumple negativamente, menoscabando estas posiciones. La similitud con cierta fórmula deleuziana es expresa: una operación no es un 
mecanismo de poder sino de deseo, una vez logrado el objetivo la operación, como tal, se “desvanece”. Los individuos involucrados deberán reformular su organización y objetivos en la coyuntura que se abre con el cumplimiento de la operación.

La naturaleza sincrónica de la operación nunca se aleja del todo de la coyuntura que la da sentido. La duración temporal de la acciones está dada por el cumplimiento (positivo o negativo) de objetivos, de modo que la operación es siempre coyuntural. Como la definición de la coyuntura es propiedad de cada operación es posible verificar en un mismo partido distintas operaciones funcionando en lógicas temporales diferentes.

En el caso de la Falange Nacional podemos distinguir claramente operaciones de distinta naturaleza, aquellas doctrinarias, que se expresaron en conducciones colaborativas de liderazgos persistentes, y aquellas pragmáticas, que tuvieron expresión en conducciones solidarias con liderazgos individualizados. Operaciones doctrinarias fueron las que integraron a los grupos católicos anecistas a la juventud conservadora y aquellas que separaron a la Falange del Partido Conservador. En ellas podemos apreciar la articulación de una élite producto del cumplimento positivo de sus operaciones. Esta conformación elítica, dentro de la cual no es posible distinguir un liderazgo individualizado aún cuando contenga en sí varios liderazgos persistentes, tendrá uno de sus más altos exponentes en la figura de Manuel A. Garretón Walker. Su alejamiento en un cargo diplomático menor y su salida de la actividad pública, motivada más por la no defensa por parte de su partido ante acusaciones que se demostraron falsas, evidencian tanto el sentido no personalista de este tipo de operaciones como su constante tendencia a perder y ganar agregados partidarios.

Por el contrario, las operaciones pragmáticas han resultados menos seminales pero más capaces de hacerse con el poder del partido y del Estado. Tal es el caso, en la Falange Nacional, de la operación freísta que culmina con la Presidencia de la República, una alianza política nueva y una debilidad doctrinaria intrínseca. Los efectos orgánicos y doctrinarios de las operaciones de liderazgos individualizados han sido, en general, negativos, dado que tanto el entramado orgánico como la producción de objetivos se van supeditando a la persistencia del liderazgo y su operación más que tomar en cuenta al partido a la colaboración con otras operaciones de liderazgos menores o expectantes. En esto la experiencia Freísta coincide en mucho con la aylwinista, la colorina y la alvearista que le son posteriores.

En lo que sigue se expone el desarrollo del análisis de caso. Utilizando como metodología la revisión de la literatura especializada en el tema, es posible distinguir entre los periodos temprano y tardío de la Falange Nacional, la forma como van funcionando y produciendo efectos las dos formas de operaciones antes descritas. El principal efecto analizado del desarrollo de estos tipos de operaciones es aquél que dice relación con la forma como se concibe y organiza la acción política organizada (la forma 
orgánica del partido) y la figura vincular del actor político o adscriptor.

\section{La etapa temprana de la operación doctrinaria: anecistas}

La fase temprana de la organización de la Falange Nacional debe mucho al proceso de formación doctrinario y organizativo que sus principales líderes tuvieron en el seno de la Asociación Nacional de Estudiantes Católicos (ANEC) (Greyson, 1968; Gil, 1969; Angell, 1974). Fundada en 1915 por los estudiantes de la Universidad Católica Eduardo Cruz-Coque ${ }^{2}$ y Emilio Tizzoni, la ANEC fue una de las primeras expresiones de la juventud social cristiana. Oscar Larson asume su asesoría en 1928 otorgándole una fuerte impronta de círculo de formación ideológica. Larson se aboca en reclutar para la ANEC a jóvenes católicos motivados por la problemática social de la época en un contexto en que los partidos políticos se encontraban clausurados por el gobierno de Ibáñez, de forma que la ANEC no sólo constituye un centro de sociabilidad sino también un espacio para el desarrollo de ese otro tipo de inquietudes. Larson pone especial énfasis en atraer a los miembros de los Encuentros de los Lunes, círculos de discusión realizado en la UC en torno a los sacerdotes Fernando Vives y Fernández Pradel, lo que implica estudiantes como Bernardo Leighton, Eduardo Frei, Alejandro Silva Bascuñán, Radomiro Tomic, Jorge Rogers, Ricardo Boizard, Julio Santa María, Manuel Francisco Sánchez, entre otros. También reclutó a jóvenes católicos de la Universidad de Chile como Ignacio Palma y Manuel Antonio Garretón Walker (Greyson, 1968; Gazmuri, 2000).

Este grupo constituiría el núcleo dirigente de la ANEC (de hecho Leighton, Sánchez, Garretón y Frei serían presidentes sucesivos de la organización)(Cash, 1986: 171) y su proyección en la Falange Nacional da cuenta de la continuidad de sentido entre ambas organizaciones, por lo menos desde el punto de vista de su élite dirigencial que se articula, debido al tipo de socialización formativa desarrollado por Larson, en un grupo colaborativo en términos de conducción.

Las actividades de la ANEC incluían, además de la formación doctrinaria, la difusión de ideas de progreso social (por medio de la Revista de Estudiantes Católicos a partir de 1931). Aún cuando la ANEC no propiciaba la entrada a la política constituía una estructura nacional bastante significativa, organizada en torno a una Secretaria Provincial contaba con grupos en varias ciudades del país. Frei Montalva, en su calidad de Secretario Provincial colaboró, por ejemplo, tanto en la realización de congresos nacionales como en la organización de grupos de la ANEC en las ciudades del sur del país. Tal experiencia, como señala Gazmuri, "no sólo le había ayudado a conocer parte del país, sino también le había abierto las puertas a una serie de contactos que, más tarde, constituirían un apoyo fundamental en la formación de los primeros núcleos provinciales de la futura Falange Nacional“ (2000: 129). Es de suponer que este tipo de experiencia se replicaba en los otros miembros dirigenciales de la ANEC. 
La ANEC, no sólo constituiría entonces una experiencia de formación doctrinaria para lo que sería la Falange Nacional, sino también una escuela de activismo y organización a escala nacional. Ambos elementos estarán contenidos en la forma adscriptiva que promoverá la Falange Nacional: el compromiso doctrinario y una estructura de grupos y delegados comunales y provinciales, aspectos que difieren de la forma organizativa del Partido Conservador, basado en asambleas provinciales (Guilisasti, 1964).

La integración del grupo anecista al Partido Conservador contiene esta diferenciación paradojal, no se cede en el no traspaso del capital político y organizacional del grupo al Partido Conservador, lo cual evidencia tanto el sentido colectivo de su acción (Tarrow) como la apreciación de estar ante una oportunidad política de alianza y un adversario, al mismo tiempo. El grupo anecista no ingresa al Partido propiamente tal, sino a la Asamblea de Propaganda Conservadora, de forma que mantienen cierta independencia en la adscripción y forma de hacer política (Greyson, 1968: 109). Esto es operado de cerca Rafael Luis Gumucio, entonces presidente del Partido luego de la caída de Ibáñez, quien ve en la integración del grupo una forma de fortalecer su posición política y las reformas que proponía, lo cual lo posiciona como uno de los vectores explicativos de la operación anecista en la Juventud Conservadora ${ }^{3}$. La alianza se da por mutuo interés posicional, por coincidencia en ciertos objetivos (como las reformas sociales propias del socialcristianismo), por evidentes cercanías culturales (Silva Bascuñán, 1949, 2008) y requiere de acciones convergentes. Gumucio moviliza al arzobispo Campillo para bloquear la oposición de Larson y Vives a la entrada en política de los jóvenes dirigentes católicos. Campillo pide a Larson que guíe al grupo al Partido Conservador, el resultado de su negativa es su traslado a Perú, el acotamiento de sus influencias en el grupo y la final vinculación condicionada al Partido Conservador, mediante una estructura paralela: la Juventud Conservadora - Falange Nacional.

La decisión final de la vinculación es de Leighton, quien se constituye en esta época como el referente orgánico del movimiento. Frei Montalva y Garretón Walker, a la sazón presidentes de la ANEC y de Acción Católica, viajan a Europa en el marco del Congreso Internacional de Estudiantes Universitarios a realizarse en Roma. El periplo incluye España (de donde Garretón Walker volverá emocionado con la oposición al gobierno de Azaña y con un nombre en la cabeza: Falange), Francia (donde asistirán a las clases de Jacques Maritain), Bélgica (donde se conocerán la experiencia política de los conservadores católicos). Como es posible ver, las experiencias de este viaje tendrán una honda influencia en la posterior Falange Nacional, no sólo a nivel de su organización sino también de su ideología; involucra, además, a los dos grandes liderazgos de la experiencia falangista. En su ausencia, el grupo dirigido por Leighton había articulado un centro orgánico (el Centro de Estudiantes Conservadores, que pasará a ser conocido como Juventud Conservadora), y un medio de difusión doctrinario (Lircay), que articulará a la élite política e intelectual del sector (Gazmuri, 2000). Ambos movimientos replican el modelo ANEC e instalan la base 
material para la operación falangista. Esto permite que la acción social desarrollada en estos contextos no sea asociada al Partido Conservador y refuerza la identidad del grupo por vía de la diferenciación accional lo que avala la critica a la praxis política conservadora (Silva Bascuñán, 2008: 16).

Esta crítica alcanza también a la forma política del partido, la Juventud Conservadora asumirá una estructura organizativa celular, muy parecida a la de la ANEC, con énfasis en cabeceras provinciales, mientras el partido continua con su forma de asambleas provinciales (Greyson, 1964: 137-139). Ambas formas apelan a la fórmula vincular de la “membrecía”, lo que puede ser considerado como una forma de adscripción de baja intensidad pero que no se condice con la práctica vincular de los anecistas. Estos asumen la forma, no el contenido del vínculo; en el mismo sentido, no será ser necesario ser Conservador para formar parte de la Juventud ${ }^{4}$.

Si bien este tipo de displicencia vincular no está del todo fuera del ethos orgánico conservador, es claro que fue leído por los falangistas como una oportunidad cuya ventaja radica en mantener posesión sobre el segmento poblacional que se terminaría disputando: la juventud católica, primero, el voto católico, después. A diferencia de la experiencia orgánica conservadora, liberal en su argumento pero disgregante en la práctica ["Estamos en una misma tienda hombres que a veces apenas nos entendemos", señalaba Boizard (1931:6)], el grupo falangista comparten formación, experiencias y objetivos. Son compactos y cooperativos. Instalados como operación dentro del tablado de la Juventud Conservadora sólo meses bastarán para que ésta pase a llamarse Falange Nacional, denotando con cada pequeño símbolo la presencia de la operación de los anecistas.

La intencionalidad de la orgánica propia de los anecistas se expresa con claridad en la circular de mayo de 1936, donde Leighton, que ocupaba el cargo de Presidente Nacional, “advertía a los centros juveniles que ellos dependían directamente de la autoridad central y no de los Directorios Departamentales Conservadores respectivos (...) que dichos centros no eran los Centros de Propaganda que se contemplan en los Estatutos generales del Partidos Conservador y debían prescindir en los asuntos que eran privativos de la vida interna de la colectividad como elección de sus directores, elección de candidatos a regidores o parlamentarios, etc." (Silva Bascuñán, 2008: 48-49). Claramente, tanto interesa una dirección férrea del movimiento como su distancia, en forma y fondo del Partido Conservador. Esta idea organizativa es refrendada en la declaración de principios de la Juventud Conservadora - Falange Nacional, publicado en 1937: “Organización jerárquica y disciplinada de nuestra juventud. Formación de sus miembros de acuerdo con nuestros principios y doctrinas. Propaganda de nuestros Ideales". Cabe notar que la noción de "miembros" permanece como figura adscriptiva.

Para 1941, el documento de bases y reglamentos del Segundo Congreso Nacional de la Falange no sólo desaparecerá la mención a la Juven- 
tud Conservadora (producto del quiebre con el Partido Conservador), la figura adscriptiva será la de "militante”. El cambio en la figura adscriptiva expresa la radicalización de la práctica de acción política llevada a cabo por la Falange, señala un cambio de sentido en esta y evidencia la superación de la etapa de la ANEC.

\section{La etapa tardía de la operación doctrinaria: falangistas}

Resulta curioso que Frei Montalva sostenga que la formación de la Falange Nacional se produjo en 1938 (Edwards y Frei, 1949: 243), considerando que la misma agrupación celebra en 1946 su undécimo aniversario (Rodríguez J., 1946). Pero tiene una razón. Para Frei Montalva, el periodo de la Juventud Conservadora había sido una etapa de gestación “en una organización (...) que con caracteres específicos naciera en 1935” (Edwards y Frei, 1949: 243).

El nombre Falange Nacional fue hecho público por primera vez en la revista Lircay, en $1936^{5}$. Si bien hay cierta oscuridad respecto a las motivaciones detrás de la adopción de un nombre tan similar al de Falange Española (1934) o respecto a su autor ${ }^{6}$, no deja de ser un claro indicador de una forma de compromiso entre principios y acción política, distinto a lo habitual dentro de las filas conservadoras (Sagredo, 2000). Los documentos de la época, tanto de Garretón Walker (1937) de Frei Montalva (1937) o de Ignacio Palma (1937) si bien señalan ser folletos de la "Juventud Conservadora de Chile”, son editados por Lircay, llevan en la tapa el símbolo de la flecha doblemente cruzada y divulgan los principios de la Juventud Conservadora - Falange Nacional (Frei Montalva, 1937).

Como fase de orgánica, el periodo tardío de la operación doctrinaria estará solapado por el despliegue de un operación pragmática en torno al liderazgo presidencializado de Frei Montalva. Como se ha señalado en otros trabajos (Vergara Vidal, 2011a) la presidencialización del liderazgo no es, inicialmente una condición literal, basta para ello la prefiguración teórica. El liderazgo presidencializado comienza a operar como tal una vez que es asociado a la carrera presidencial, lo que en el caso de Frei Montalva se da antes de cualquier nominación formal. El solapamiento de los procesos, doctrinario y pragmático, es posible de apreciar en los slogans "Revolución en orden”, utilizado para definir el proceso interno de intenso activismo electoral, de colaboración con el Partido Conservador y de reclutamiento de militantes para la Falange (Greyson, 1964: 132), que define la concreción de la operación doctrinaria en orgánica; y el slogan "Revolución en Libertad”, utilizado en la campaña presidencial de Frei de 1964. Ambas son frases de campaña, una interna y la otra externa, en esto mismo se ve donde están los escenarios de lucha que cada tipo de operación reconoce.

En este periodo la Falange se territorializa apoyando las candidaturas conservadoras. Frei trabaja en Iquique apoyando con viajes y discursos a las candidatos del Partido Conservador; Tomic y Juan de Dios Carmona 
lo hacen en Antofagasta; Ricardo Valenzuela trabaja políticamente en Rengo; Manuel Francisco Sánchez y Garretón Walker lo hacen en Santiago; Boizard organiza un Centro de la Juventud en Talca; Palma y Leighton viajan por el país difundiendo el movimiento. Etc. La expansión del movimiento se estructuró sobre la base de la formación de los Centros de la Juventud Conservadora - Falange Nacional los cuales constituían la "célula fundamental” del movimiento. Como señala Greyson: "Sobre ella descansaban las actividades locales de la juventud. El presidente de los Centros era responsable ante un presidente provincial, elegido anualmente por una Junta Provincial, que también era utilizada como cuerpo consejero: Luego los presidentes provinciales, quienes eran los funcionarios más importantes de la organización en sus regiones, quienes rendían cuentas al presidente nacional, la "suprema autoridad ejecutiva". En la cumbre de la pirámide organizativa se hallaba la Junta Nacional, formada por los presidentes provinciales o delegados y cinco miembros elegidos por el Comité del Partido Conservador, quien se hallaba encargado de supervisar las decisiones políticas de la Juventud” (Greyson, 1968: 135-136). Como es posible la orgánica propia había tomado una forma nacional. Este esquema guardaba una coherencia estructural con las provincias electorales del país, por lo que podemos suponer la orientación de sus esfuerzos.

Para 1937, Leighton es designado ministro del Trabajo del gobierno de Alessandri, mientras Garretón Walker es elegido diputado por Santiago en las papeletas conservadoras, mientras seis diputados conservadores adscribieron al movimiento ${ }^{7}$. Para la convención de octubre de 1937, el teatro Caupolicán recibió 10.000 delegados de todo el país que constató que la Falange tomaba la forma de una fuerza política en sí. Lircay, calculaba en 20.000 miembros distribuidos en 250 centros en el país. La adscripción política asume para estos jóvenes conservadores la forma de una actividad militante, la máxima figura del compromiso doctrinario (Cash, 1986).

Parte de las estructuras que asume la Falange Nacional, además de la de los Centros, también dan cuenta de ello. Bajo el mando de Garretón Walker, Ignacio Palma y Jorge Rogers los jóvenes falangistas recibieron uniformes y estructura de grupos de choque. En teoría, los equipos debían estar conformados por cuatro falangistas, cada cuatro equipos constituirían una sección y cuatro secciones constituirían un grupo. Esta organización de 54 militantes debía estar conducida por un brigadier. Rogers fue el encargado de poner en actividad esta nueva estructura a la que se suma los "exploradores” compuestos por menores de 15 años (Greyson, 1968: 146).

Aunque no hay datos que permitan afirmar que estas estructuras persistieron más allá de un año y o hay registros de que se hayan participado en acciones concretas, su organización da cuenta del grado de compromiso que la práctica política comenzaba a exigir a los jóvenes conservadores. Tanto Garretón Walker como Palma no prevenían del grupo conservador de la Universidad Católica sino del grupo Renovación de la Universidad de Chile, de carácter "más combativo" según Larson (Gazmuri, 2000: 120). En tal calidad se habían enfrentado al izquierdista grupo Avance e 
ingresado a la ANEC en 1928, motivados por la nueva orientación que ésta tomaba bajo la dirección de Oscar Larson.

Como señaláramos anteriormente, el viaje de Garretón Walker y Frei Montalva a Europa entre 1933 a 1934, conllevará cierta influencia del catolicismo belga en la concepción de la práctica política y el carácter de la adscripción que toma forma en la Falange Nacional (Silva Bascuñán, 2008: 55). Este aspecto es refrendado por Federico Gil para quien durante el periodo de dirección de Garretón Walker, la Falange "recibió la fuerte influencia del movimiento belga conocido como rexismo, el cual, aunque católico, resultaba bastante contaminado de nazismo” (Gil, 1969: 288). Para Gil, “era sorprendente la similitud entre el famoso programa de veintiséis puntos de la Falange española (...) y la declaración de principios de la Falange chilena en el periodo de Garretón” (Ibid.), programa que no tuvo modificaciones hasta 1948. Por cierto hay entre ambos documentos ciertas similitudes conceptuales, como aquellas que dicen relación con el destino nacional, orden nuevo y otros, pero no se puede sostener una coincidencia exacta. Mientras el documento de los 27 puntos de la agrupación española señala: "La vida es milicia y ha de vivirse con espíritu acendrado de servicio y de sacrificio", la Falange Nacional sostiene en su punto 24: "Para la construcción de este orden nuevo, Falange Nacional no pide una adhesión pasiva a un programa sin vida: exige una fe inquebrantable en el destino de la Patria. Sacrificio y abnegación son los sellos distintivos de nuestra cruzada de justicia y hermandad"9 .

Como es posible constatar en el punto 18 de la ya mencionada declaración de principios de 1937 se reitera la idea de "Abnegación y Sacrificio. Al servicio de Chile y de Dios”. El punto 17 contiene el principio de organización jerárquica y disciplinada de la juventud. Obviamente el sentido adscripctivo de la Juventud Conservadora - Falange Nacional es más exigente que el del Partido Conservador al cual están agregados. Los principios abogan a un correlato social también diferente: "4.- Estado Nacional y jerárquico por encima de grupos, partidos y clases; 5.- Política ética y dinámica. Ni la democracia liberal, ni dictadura fascista o socialista; 6.Defensa de la libertad dentro del orden; 8.- organización corporativa de la sociedad. Sindicato libre en profesión organizada, etc.”. Como es posible ver, la Juventud Conservadora - Falange Nacional coincide con los planteamientos de un corporativismo acorde a la buena salud de corporativismo europeo belga, alemán, austriaco y español (Greyson, 1964; Fariña, 1987). A través de Lircay, entre los años 1934 y 1938 figuras conductoras del movimiento como Garretón Walker, Ignacio Palma, Bernardo Leighton, Fernando Durán y Manuel Francisco Sánchez promoverán las ideas corporativistas, de raíz cristiana, pero que contienen una fuerte impronta de autoritarismo político con base en un Estado Nacionalista y autoritario y en las corporaciones (Fariña, 1987). Eso, y la centralidad que asume la acción política, es lo que tiene un correlato en la forma orgánica en el inicio de la Falange Nacional y que Gil (1969) identifica con la conducción de Garretón Walker y del cual Greyson rescata su significativo lema: "Revolución en orden"10. 
La decantación como organización independiente se dará en el marco de la nominación del candidato conservador a la Presidencia de la Republica en 1938. La oposición a Ross por parte de los diputados y delegados de la Juventud Conservadora - Falange Nacional, el llamado a libertad de acción a sus militantes y la posterior derrota del candidato conservador llevaron a la Junta Ejecutiva del Partido Conservador a decretar la reorganización de la Falange. La obvia oposición de su presidente (Garretón Walker) determinó la desagregación del movimiento del espacio conservador: "La Falange Nacional declara definitivamente que no aceptará el veredicto de reorganización y continuará en busca de las metas que la han inspirado desde su fundación. Por tres años hemos interpretado el pensamiento de miles de chilenos que buscan un futuro mejor para el país. Ahora hemos proyectado nuestro movimiento a un plan más amplio aún (...) iniciamos una nueva fase con renovada fe y entusiasmo" (Greyson, 1964: 158). Este es, para Frei, el punto de inicio de la Falange Nacional y lo es desde el punto de vista de la autonomía de la organización.

Los estatutos de 1939 de la Falange Nacional establecen ciertas adecuaciones a la estructura orgánica y adscriptiva. La figura adscriptiva tendrá una acepción característica y propia en el "falangista", que define al militante de la Falange puesto que "la Falange es una actitud" (Falange Nacional, 1940). Esta figura contiene la carga simbólica dada a la pertenencia de la Falange Nacional. La mencionada carga simbólica implica tres tipos de pertenencias: la orgánica, la ideológica y la generacional ${ }^{11}$.

Los estatutos de 1939 establecen en el artículo primero del título I: "Son falangistas todos los chilenos que firman los Registros de la Falange Nacional, prestan el juramento respectivo y cumplen con los requisitos establecidos en los presente estatutos. Aquellas personas que, sin prestar el juramento de estilo adhieran a la Falange, colaborando con ella en alguna forma concreta se considerarán "Falangista adherentes" (Falange Nacional, 1940: 11). De este modo las figuras adscriptivas se amplían a los colaboradores. Nótese que esta forma de adscripción no requiere más que la adhesión práctica, lo cual implica una clara intencionalidad de aumento de caudal orgánico. El relato del desarrollo del Congreso Provincial de Santiago hace también hincapié en esta ampliación de los activistas "Ciento ochenta y tres hombres nuevos. Eran dirigentes comunales, pero no los dirigentes ya conocidos. Era un vasto cuerpo de dirigentes falangistas, que son los que están en el corazón mismo de la provincia y de la Falange, luchando y abriendo camino. He ahí una fuerza, verdadera, real, profunda, indestructible. He ahí la gran revelación del Congreso” (Ibid.:4)

En términos de la acción política el artículo segundo señala: “Todo falangista desarrollará obligatoriamente dos órdenes de actividades: a) «políticas», y b) «ejecutivas». Hará «acción política» participando en la fijación del rumbo y las directivas políticas del Movimiento y en la designación de sus autoridades según se indica en este Estatuto, a través de los «Centros» de organización democrática. Hará «acción ejecutiva» trabajando en alguna de las actividades especializadas que se encaminen al mejor 
desarrollo y difusión del Movimiento a través de los «Departamentos» organizados, en lo posible jerárquicamente y cuya misión no directiva está llamada a ejecutar y llevar a la práctica los propósitos señalados por las autoridades políticas” (Falange Nacional, 1940: 11). El carácter obligatorio de los tipos de acción va en el mismo espíritu que el compromiso solicitado en el periodo que los unió al Partido Conservador. Es de notar también que la estructura orgánica de la Falange sigue siendo espejo de al división administrativa y electoral del país, como reza el artículo tercero: "El falangista, sin perjuicio de su registro y trabajo en los Departamentos ejecutivos a que vocacionalmente pertenezca, estará empadronado en el centro que corresponda a su inscripción electoral, donde irá a sufragar en las elecciones internas de la Falange, a participar en su dirección política, y a contribuir al mantenimiento de la organización mediante el pago de la cuota” (Ibid.).

En lo que refiere a la forma orgánica un cambio llamativo respecto a la estructura de la Juventud del Partido Conservador - Falange Nacional es que el nivel de base de la agrupación es ahora la comuna y no la provincia. El Centro de la Juventud Conservadora pasa a ser el Centro de la Falange Nacional, pudiéndose organizar más de un Centro en cada comuna e incluso Centros Intercomunales, siempre bajo la égida de una Junta Provincial (Falange Nacional, 1940: 13). En los niveles superiores de la organización se replica la anterior forma orgánica, incluidos los departamentos asesores a los cuales se suma una Juventud de la Falange Nacional y la división entre una Falange Masculina y una Falange Femenina.

Otra innovación, de clara ascendencia ideológica corporativista serán las Corporaciones Falangistas, secciones de clasificación funcional en las cuales están obligados a inscribirse todos los falangistas sin cargos orgánicos o de elección popular (Título IV, Art. 19). Esto establece un esquema territorial/funcional que permanecerá en las estructuras partidarias lo largo del tiempo con variaciones respecto a la preponderancia de cada ámbito respecto al otro. Ambos implican dos formas de inserciones del trabajo proselitista. Si bien el aspecto territorial variará de acuerdo a las modificaciones del sistema electoral del país, dando forma a la estructura administrativa del partido, la mayor o menor importancia del aspecto relacionado con la inserción en el ámbito funcional dependerá del grado de vida colectiva que es capaz de dinamizar en cuanto tal.

Los acuerdos del Congreso de Santiago contienen la figura orgánica del "núcleo", que podía estar compuesto por no menos de tres falangistas y no más de 15. De exceder los 15 falangistas el "núcleo" pasa a ser un "Centro”. Siendo el territorio base de la acción política la Comuna, la creación de los núcleos se recomendaba en los sectores suburbanos y rurales, previa autorización de la Junta Distrital. Otro acuerdo del congreso es "el uso obligatorio para todos los falangistas, hombres y mujeres, de la insignia en todas las circunstancias” (Falange Nacional, 1940: 32).

Como vemos el despliegue orgánico de la Falange Nacional para 1940, por lo menos a nivel de imaginería, es considerable. Hay allí una 
práctica que está ajustando su forma a su función. Hacia fines de ese año se reemplazará Lircay por el periódico Falange (Gazmuri, 2000) que no dará los resultados esperados y que a su vez será reemplazado por Nuestro Tiempo como periódico bimensual hasta 1945. Como tampoco se vería reafirmado este esfuerzo orgánico por los resultados electorales de 1941. Sin el apoyo económico del Partido Conservador ni el apoyo publicitario del El Diario Ilustrado, los falangistas eran el principal recurso del nuevo partido.

Concentrando su acción electoral en Santiago, Iquique, Valparaíso, O’Higgins y Chiloé los resultados echaron por tierra los cálculos de Garretón Walker y el Comité Electoral Nacional: esperaban 10\% y obtuvieron 3,44\% (Gazmuri, 2000: 262-263), 15.553 votos a nivel nacional. Esto se tradujo en la mantención de sólo 3 de los 6 cupos de diputados que habían obtenido en 1938. Garretón Walker mantuvo su escaño, a lo cual se sumaron Tomic (Iquique) y Jorge Ceardi (Valparaíso). Estos resultados implicaron la salida de Garretón de la Presidencia Nacional y la llegada de Frei.

Para el segundo Congreso de la Falange Nacional de 1941, que encabezó Frei desde la Presidencia Nacional, los núcleos había pasado a ser fracciones (con un número máximo de 20 miembros) y la Falange Nacional contaba con 28.547 militantes masculinos y 7.680 militantes femeninas (Falange Nacional, 1941). Garretón Walker dejaba la conducción de la Falange con los logros de haberla dotado de una organización nacional y una militancia que se acercaba al 6\% de la población del país en ese momento, y la meta para el año 41 de crecer en 15.000 militantes más.

Los esfuerzos que caracterizaron el periodo de la presidencia de Garretón Walker fueron, sobre todo, expresión orgánica de un proyecto doctrinario. La Falange de este periodo está comandada por una operación doctrinaria, siguiendo esta línea se constituye en "una cruzada", "una actitud”, algo "más allá de derechas y de izquierda" (Falange Nacional, 1941). En el periodo de Frei Montalva (1941-1945), la dirección del movimiento asumirá un enfoque levemente más pragmático, marcado por el aumento de los pactos en pos del incremento de su influencia nacional. Esto llevará a algunos falangistas a asumir responsabilidades en el Estado, lo que le permitirá contar con mayores recursos políticos y visibilidad pública, lo cual es la base del proceso de estabilización de la élite partidaria que articulará la operación pragmática en torno a Frei. Paralelo a esto Leighton y Lorca inician el trabajo político en el mundo sindical que verá sus primeros frutos en la elección de Lorca en el comité ejecutivo de la CTCh.

Los nuevos énfasis no se desarrollarán a expensas de la doctrina o de la forma orgánica. En lo primero la carta de entrada de los falangistas serán los "Veinticuatro Puntos Fundamentales de la Falange Nacional" (Greyson, 1968: 207; 473-481); en lo segundo, las reuniones semanales de asambleas y centros de estudio constituirán el principal instrumento de socialización política. En el mismo sentido, la fundación de la Editorial del Pacifico en 1945 permitirá la publicación y difusión de sus planteamientos y el soporte del fomento doctrinario (Ibid,: 208). Desde esta casa editora 
comenzará a publicarse Política y Espíritu que suplirá el papel del Lircay y que es actualmente la publicación doctrinaria del Partido Demócrata Cristiano.

Estos incrementos en la capacidad de captación y difusión de la Falange no tendrá un correlato exitoso en lo electoral, pero la estabilización de sus resultados en este plano y la calidad de la dirigencia falangista permitirá aumentar su influencia e inserción el aparato estatal (Huneeus, 2003; 2010). En las elecciones municipales de 1944, primera campaña donde presentan candidatos en todo el país, la Falange sólo obtuvo algo más que 20.000 votos. Las elecciones parlamentarias de 1945 le otorgan 11.565 votos, lo que en concreto implica que en el periodo de Frei Montalva la Falange perdió cerca de 4.000 votos, un cuarto de su caudal electoral inicial y mantuvo sus tres diputados. Sin embargo su incidencia pública se incrementó, lo cual representa otra forma de ganar, Si bien en el periodo entre 1941 a 1953, la Falange mantendrá siempre 3 diputados, sus votos se verán duplicados de 11.565 a 22.353, en 1953 (Greyson, 1968: 209-370).

La estabilización de la débil efectividad electoral de la Falange no permite hablar de la conformación de un grupo parlamentario. Los nombres de los parlamentarios electos no persisten en el periodo 1941-1956. Ante esta particularidad, su proceso de elitización se desarrolla en torno a los dirigentes que son convocados a cargos ministeriales y de jefes de servicios durante los gobiernos del periodo 1941 a 1953 y a los regidores y alcaldes electos en el mismo periodo. Es este el principal motor de la visibilidad e incidencia que adquirirá la Falange post 1941, además de las negociaciones vinculadas a su apoyo a las candidaturas presidenciales externas, lo que está vinculado. Si bien la Falange no dependía del Estado, su permanente participación en gabinetes y el desempeño en éstos fue dando visibilidad nacional a los dirigentes falangistas ${ }^{12}$. Esto les da la posibilidad de "alimentar a numerosos funcionarios dentro de la burocracia estatal" (Greyson, 1968: 193).

El obvio pragmatismo de este tipo de alianzas tensionará el proyecto doctrinario falangista, cada alianza implica una adecuación de la interpretación doctrinaria, lo cual dará pie a una discusión permanente en las filas falangistas, entre la fidelidad a los principios por medio del "camino propio" y la fidelidad a los mismos por medio del “cumplimiento” de los objetivos partidarios. Principios, medios y fines serán los elementos de una discusión que tendrá como corolarios posteriores rupturas o desagregaciones.

Este el punto de inflexión entre las operaciones doctrinarias y pragmáticas, a partir de las discusiones de abril de $1946^{13}$ es posible contar con la presencia de un programa pragmático cuyos cálculos están en la alianzas que permitan pasar de la incidencia decisional a la mayoría electoral. Por su parte el programa doctrinario apostará a las alianzas que le permitan a la Falange seguir siendo fiel a sus principios, es lo que se llamará, por un tiempo "línea popular", sustentada en el trabajo de Leighton y Eugenio Lorca hacia los sindicatos lo que implicaba un acercamiento con la izquierda y asumir la estructura de una “organización de masas” (Greyson, 1968: 
235). Tras esta postura se sumaron Jorge Rogers, Alberto Bahamondes y Rafael Agustín Gumucio, entre otros, que venían de una experiencia de colaboración con la izquierda dentro de los gobiernos radicales. Como es posible apreciar por su composición, gran parte de esta "línea" queda conformada por quienes había encabezado la fase temprana de la operación doctrinal. La postura de la independencia entre derechas e izquierdas sería sostenida por Radomiro Tomic. Tal fue la postura ganadora, Leighton renunció a la presidencia nacional y asumió Tomic.

La derrota de la postura de acercamiento con los partidos de izquierda no será completamente asimilada, quizá porque representa la derrota de una operación fundante y que persistirá en el tiempo, cada vez con menor incidencia y capacidad. Esta fisura reaparecerá una y otra vez dentro del partido Demócrata Cristiano, hasta que, hacia 1967, una vez debilitado el liderazgo personalizado de Frei Montalva, cumplida su presidencialización, en medio de su gobierno y producirá la articulación de dos facciones internas (“rebeldes” y “terceristas”) que se desagregarán del PDC.

Por otra parte, la derrota de la postura "popular" en 1946 evidencia que, si bien la experiencia de colaboración gubernamental había servido para "alimentar" el partido (Greyson, 1968) aumentando su incidencia publica, esto no había sido suficiente para articular un élite como tal. Sin embargo, a pesar de la falla en la corroboración, la experiencia sí había servido para el desarrollo de la capacidad incidente de quienes participaron como ministros y jefes de servicio en la colaboración.

Acorde con la postura ganadora, Tomic llevaría al Falange a apoyar al candidato conservador Cruz Coke quien representaba una ideología social cristiana. Tal postura encontró oposición en Frei, Rogers, Valenzuela, Sánchez y Palma quienes apoyaban la idea de un único candidato centrista, radical (González Videla). El "Congreso de los Peluqueros” (Agosto de 1946) definiría la derrota también de esta postura por 43 a 41 votos de la Junta Nacional y el apoyo a Cruz-Coke.

La experiencia de haber puesto sobre sus hombros la campaña presidencial de Cruz-Coke (que dividió también al sector conservador) permitió una importante visibilidad de la Falange Nacional y el acercamiento de otros sectores social cristianos que más tarde se incluirían en la formación de la Democracia Cristiana. Más que mal la candidatura de Cruz-Coke obtuvo el 29,8\% de los votos nacionales, mientras el candidato de los conservadores y liberales (Fernando Alessandri) obtuvo el 27,42\% (Pereira, 1994: 99). La diferencia favorable a Cruz-Coke se obtuvo en la Región Metropolitana y en la provincias del Centro del país, mientras en las otras tres zonas (Norte, Centro Sur y Sur), Alessandri superó a Cruz-Coke. La suma de ambas candidaturas, a su vez, superó el 40,23\% obtenido por el candidato vencedor González Videla. Este hecho alejó aún más a conservadores y falangistas. Mientras unos veían decrecer su capacidad orgánica y electoral frente al nuevo partido, los otros se veían con la posibilidad de administrar 
una creciente influencia a pesar de su estancamiento electoral. Por cierto, la solución de este último aspecto constituiría la base de la transformación de la pequeña Falange en un partido de masas.

Para 1948, las afinidades entre la Falange Nacional y el sector social cristiano del Partido Conservador se hicieron más evidentes al oponerse ambos a la promulgación de la "Ley de Defensa de la Democracia”, iniciativa apoyada por el Partido Conservador y que dejaba fuera de ley al Partido Comunista. La corriente socialcristiana, conducida por Horacio Walker, se hará con 11 de los 32 diputados conservadores elegidos en 1949 (Pereira, 1994: 242), una minoría respecto del sector que había apoyado la Ley Maldita (tradicionalista, 21 diputados). La actitud del sector socialcristiano de no renunciar a la Junta Ejecutiva y de censurar a 9 miembros del sector tradicionalistas que integraban la Comisión de Unidad Conservadora llevó a la constitución de dos Juntas Ejecutivas y la división práctica del Partido Conservador. Esto se haría formal en la lección de regidores de 1950 donde cada junta presentó listas separadas: una social cristiana y una tradicionalista. El pacto de los socialcristianos, la Falange y los radicales para esa elección evidencia la cercanía que comienza a cuajar. Aún cuando en las elecciones presidenciales de 1952 conservadores social cristianos y Falange Nacional apoyan al candidato radical (Pedro Enrique Alfonso), Horacio Walker patrocina un voto político para conformar un Frente Demócrata Cristiano con la Falange Nacional, sustentado en la idea de que la unidad conservadora sólo es posible en torno al ideal social cristiano y a "una posición política de avanzada, pasando por encima de derechas e izquierdas” (Pereira, 1994: 253)

La idea de la conformación de una sola fuerza social cristiana comienza a gestarse en 1953. Tanto los presidentes de los partidos conservador y falange nacional, como los congresos (sexto de la falange) y convenciones (conservadora de septiembre) explicitan el acuerdo en pos de la unidad (Greyson, 1968: 294-296). El resultado de esto es la formación de la Federación Social Cristiana que organiza la cooperación entre los partidos, lo cual se dará en la Directiva Nacional de la Federación. La fundación de la Federación atraerá a un par de diputados (Musalem y Lascar) del Partido Nacional Cristiano, que había surgido en apoyo de Ibáñez.

A la par de esto, Ibáñez buscó el apoyo de Frei para la crisis social que enfrentaba su gobierno, el que le propuso organizar una nuevo gabinete. Si bien la idea fue detenida por los adherentes de Ibáñez, este hecho da cuenta de la incidencia de Frei en la política nacional. Su visibilidad y eficiencia en su papel de Ministro de Vías y Obras Públicas y en su papel de Senador, colaboraron con un prestigio que era corroborado por el llamado de Ibáñez.

Para Greyson, este hecho altera la táctica de la Falange. Greyson hace notar el papel jugado por Jaime Castillo Velasco, director de Política y Espíritu, “quien sucedió a Manuel Garretón Walker como el más notable ideólogo del partido” (Greyson, 1968: 300; Castillo Velasco, 1968, 1971), 
en el uso simbólico de la figura de Frei. Más allá del nombramiento fallido como jefe de gabinete, el reconocimiento en sí mismo se extendía al conjunto del pequeño partido. Por cierto es notable que una figura preponderante (no el jefe) de un partido con una fuerza electoral mínima (3\%) fuese convocada a tal responsabilidad. transforma la anécdota en una corroboración personal (del liderazgo de Frei) y grupal (lo extiende al partido). Hecho esto convoca a la falange y a la Federación a una "renovación auténticamente nacional” (Ibid.: 301).

$\mathrm{Al}$ mismo tiempo que coloca a Frei como "el ejemplo de la fórmula para el éxito”, y en la misma línea de Garretón y de Tomic, Castillo llama a la obtención de "nuestros propios objetivos" traficando la fórmula doctrinaria a una fórmula pragmática. Como cita Greyson: "la estricta disciplina partidaria y la difusión son el prerrequisito de la victoria ideológica. Y si los social cristianos han de proveer la dirección en todos los grandes problemas nacional, deben evitar alianzas que corroerían y atenuarían su doctrina” (Greyson, 1964: 302). Con esto Castillo personifica en Frei, la empresa del camino propio, que Garretón había depositado en el partido. De esta manera, la corroboración electoral y política de Frei, será la corroboración de la propia Falange. Dado que se encuentran en una Federación, Castillo deposita en Frei el capital político de la misma, por sobre, por ejemplo, de otros liderazgos como el de Leighton o Rafael Gumucio que, en ese momento, ocupaba la presidencia de la Federación.

La línea expuesta por Castillo Velasco será, a su vez, corroborada por la negativa de la Federación Social Cristiana a sumarse al Frente Nacional del Pueblo, compuesto entre otros por el Partido Socialista de Chile y el Partido Comunista. La línea ideológica que inspirará a la Falange es definida por Castillo como nacional y popular, ello será reafirmado en una declaración política de la Falange julio de 1956: "la Falange continuará preparándose para sus altos designios (un programa "nacional y popular”), y ordena a todos sus militantes asumir un puesto en el partido, que corresponde a su capacidad y vocación” (Greyson, 1968: 307)

Para 1955, en el marco del Congreso Internacional Demócrata Cristiano, organizado en Santiago por la Federación Social Cristiana es posible apreciar la fuerza de la falange Nacional respecto del Partido Conservador Social Cristiano. Mientras éste presenta 172 delegados, la Falange Nacional presentará 323 (Reyes Vicuña, 1957: 78-95). El listado de delegados nos ofrece también una visión sobre la élite falangista, hay dos ausencias notorias, las de Garretón Walker y la de Alfredo Lorca. Mientras el listado conservador nos arroja pocos nombres reconocibles en la posterior historia de la Democracia Cristiana (Horacio Walker, Andrés y Alberto Zaldívar, Clemente Pérez) o representación de asociaciones; el listado de la Falange está lleno de ellos. Esto nos permite constatar la influencia de la experiencia falangista en la conformación de la élite demócrata cristiana y su rol preponderante respecto a los conservadores social cristianos $^{14}$. El llamado de Castillo no se agota, en este sentido, en la Falange. 
Mientras en su homenaje a Rafael Luis Gumucio, Alberto Bahamondes habla de “nosotros los falangistas” (Reyes Vicuña, 1957: 355), en su discurso, Frei, que preside el congreso, instala otra figura: "somos los demócratas cristianos (...) portadores de un mensaje de libertad” (Ibid.: 358), y reafirmando la concepción nacional y popular de Castillo, por sobre izquierdas y derechas, añadiendo: “ Yo diría que ésta es la hora de la democracia cristiana, porque las fuerzas históricas están dentro de su sentido y de su corriente” (Ibid.: 362). La misma identidad demócrata cristiana será defendida por Frei en la Asamblea Inaugural de la Primera Conferencia Mundial de Movimientos Demócrata Cristianos en 1956 (Ibid.: 367)

El traslado electoral de Frei en 1957, de la senatoria de Atacama y Coquimbo hacia Santiago estaba en el camino de su instalación presidencial, así lo vio Eduardo Cruz Coke, también parte de la Federación Social Cristiana y senador por Santiago en el cupo conservador de la Federación. La oposición de Cruz Coke, quien habló de las “mil mezquinas traiciones y mentiras por parte de los falangistas” (Greyson, 1964: 308) pone en evidencia a una falange crecientemente hegemónica. Los resultados de las elecciones parlamentarios de ese año dieron a la Falange el 10\% de los votos, un senador y catorce diputados frente al senador y el diputado del partido conservador social cristiano. En este punto la formación del Partido Demócrata Cristiano y presidencialización de Frei van de la mano (PDC, 1970:53). La preponderancia falangista llevará al nuevo partido su sentido de la política (vocación de libertad, popular y moral) (Reyes Vicuña, 1957: 361) y su estructura política (Hawkins, 2010).

\section{La etapa temprana de la operación pragmática: freístas}

Acorde con la cultura partidaria chilena, tanto la Falange Nacional como el PDC parecen organizaciones altamente centralizadas donde "resulta suprema la influencia de los dirigentes máximos” (Gil, 1969: 296), esto da sustento a la tesis de la alta institucionalización (Huneeus, 2003; 2010). En gran parte esto se debe a los marcos cooperativos entre operaciones que se mantuvieron vigentes desde el inicio de la operación doctrinaria. Pero estos marcos comienzan a perder vigencia cuando la competencia cuestiona los sentidos de la conducción cooperativa y reabre la composición de la élite partidaria bajo la presión de una operación de corte pragmático.

Como se ha tratado en anteriores trabajos, el origen de una elite partidaria, corresponde al desarrollo y personalización de capacidad incidente dentro del partido (Vergara Vidal, 2011b; 2012). Esta capacidad puede ser nominal a una persona o a un grupo, puede provenir de la posesión de un cupo parlamentario, la dirección de una revista, la representación de un movimiento gremial, una posición socialmente destacada como la de columnista, un liderazgo local, etc. Esta capacidad implica el ejercicio de influir significativamente en las decisiones sociales y partidarias y, como tal, es uno de los elementos de los liderazgos. El liderazgo aparece cuando 
esta capacidad incidente es puesta en función de una operación individualizada de incidencia y visibilidad.

La élite falangista se conforma en torno a estas capacidades, se evidencia en la literatura por medio de la persistencia de ciertos nombres, como Leighton, Tomic, Garretón Walker, Rogers, Boizard, Carmona, Palma, Frei, etc. Nombres que aparecen como incidentes en momentos claves, que orientan las decisiones. Colabora con esto la extracción social común de la dirigencia falangista, predominantemente de clase media, con una educación profesional y con fuerte lazos de amistad entre ellos (Angell, 1974: 188-189; Gil, 1969: 294; Cash, 1986). Pero no se agota sólo en el ámbito interno de la Falange. Muchos de estos personajes son los motores que permiten incrementar la incidencia de la Falange en el ámbito nacional, por medio de los cargos parlamentarios y sus negociaciones, los ministerios, las jefaturas de servicios o la representación sindical (casi simbólica). Otros, como Castillo Velasco, darán forma o reinterpretarán la línea ideológica del partido.

Pero este conjunto de capacidades incidentes no se conformará como élite partidaria sino hasta que persistencia de estos nombres se estabilice. Este proceso se desarrolla, en la Falange, ligado a la estabilización del grupo parlamentario y la mayor incidencia pública por medio de ministerios y jefaturas de servicios. Como tal proceso está dentro de un sentido operativo doctrinario, la cooperación es mayor, impidiendo un cierre. Sin embargo el gran impulso al cierre elítico lo dará el proceso de constitución de un partido unitario de los socialcristianos (1953-1957); proceso orgánico e ideológico que va a la par, si es que no es parte, de la operación del liderazgo de Frei Montalva.

Esta operación unifica la capacidad incidente “desperdigada” en distintos liderazgos, y configura una acción colectiva unívoca de con cabeza y objeto en Frei Montalva. Las frases elogiosas en torno a la persona de Frei (“el hombre del destino”, como señala Boizard) (1963: 293 ss), que apoyan esa suerte de mito de un político trasfigurado por la espiritualidad y el deber, sin carecer de fundamento, están muy al tono de la imagen de "líder total" de la época ${ }^{15}$. Funcionan en ese sentido aún cuando, a esas alturas, el gran trabajo de articulación del partido a nivel doctrinario y orgánico, había estado sobre los hombros de Leighton, Palma y Garretón, principalmente. A diferencia de Tomic, Leighton, Garretón y Palma, que por problemas personales (usualmente financieros, como señala Greyson (1968: 315) dejaban esporádicamente su actividad en el partido, Frei había sido persistente en eso, a pesar de obtener una banca de diputados recién en 1949 luego de tres derrotas consecutivas.

La presidencialización efectiva y la personalización del liderazgo de Frei (1958) catalizan, finalmente, el proceso de cierre elítico, pues pone a la operación política en función de un objetivo individualizado. El partido cuya propuesta de conducción nacional había sido escasamente corroborada electoralmente, coloca en la figura de Frei el destino de su misión. 
No sólo es el primer candidato presidencial falangista, como tal recibe el apoyo cerrado de la élite partidaria. Todas las capacidades incidentes son puestas en función de la operación de este liderazgo, lo cual jerarquiza los liderazgos internos. El largo camino de los falangistas a la presidencia colabora también con la ausencia de "fisuras" o desagregaciones elíticas respecto del apoyo al candidato. Esto dice mucho de la voluntad de la élite falangista, materializada en colaboración persistente, por el logro final. Esto no se reproducirá, por ejemplo, en la candidatura presidencial de Tomic e, incluso, con respecto a Frei en el gobierno. En este sentido, no es liderazgo de Frei el que se debilita una vez lograda la presidencia y, una vez, puesto en su control los amplios recursos del Estado. Por el contrario, son las élites democristianas las que fisuran los marcos de la colaboración que les había resultado tan efectiva. Sus capacidades incidentes, su capital político es enfocado entonces en direcciones divergentes.

El cambio que opera la presidencialización del liderazgo de Frei trasmuta el sentido de la élite falangista, desde una posición de autoconvocados por la consecución de un ideario o programa, a una posición de colaboradores en el logro de un objetivo político concreto. En tal sentido, los nombres que vemos con persistencia en los momentos claves, pasarán a operar el liderazgo de Frei, por distintos medios. Aparecen entonces los textos que ponen de realce la figura de Frei, se le asigna el papel de ejemplo a seguir (Castillo), de personaje mundialmente reconocido (Boizard, 1963), de jefe indiscutido. Los otros liderazgos serán subsumido en esta empresa, Leighton pasará a ser el "hermano”, Garretón Walker muere en 1956, Lorca pasará de activista sindical a diputado freísta, etc.

La corroboración electoral de esta estrategia la profundizará, el crecimiento electoral de 1957, la campaña presidencial de 1958 y la victoria de 1964 colaborarán en esto. La élite falangista/democristiana se materializa como tal en el proceso de operación del liderazgo de Frei (PDC, 1970: 53). El impacto de esto sobre la forma de la militancia será también importante. Los falangistas trabajaban en pos de un programa y un ideario, el falangista constituía un cuadro militante, fuertemente ideológico ("la falange es una actitud"). El "falangista inicial" se auto designa como tal (Falange Nacional, 1940). Los demócrata cristianos trabajarán en pos de un líder y un programa, en cada mochila, como señala Lira Massi (1965), ya no llevan el bastón de un general, llevan un bombo. El demócrata cristiano es señalado como tal por el partido, que es el instrumento de la operación freísta. Este giro en la forma de designación de la figura adscriptiva, ya se encontraba en los "Estatutos de la Falange Nacional (Partidos Popular Cristiano)" de 1954, el que señala en su artículo primero: "Es falangista la persona cuyo ingreso al Partido ha sido aceptado por el Directorio del Centro que corresponda a su residencia o al lugar en que desarrolle su trabajo" (Falange Nacional, 1954: 7). La figura del "falangista tardío" no sólo subsume la aceptación individual de principios en la aceptación corporativa, es el Partido quien elige a sus militantes; sino también hay una fuerte impronta funcional y territorial. Este aspecto es profundamente importante pues nos señala un aspecto muy característico de la Falange que afecta la 
formación de su élite y de su militancia: el sustrato territorial. De modo que las diferencias entre el "falangista inicial” y el "militante demócrata cristiano" son construidas entre 1941 y 1953, el periodo inicial de la inserción electoral de la Falange.

El documento de 1954 profundiza la ligazón territorial: “3. Los falangistas desarrollarán acción propiamente política, participando en la fijación de las posiciones del Movimiento y en la designación de sus autoridades sólo a través de los Centros, Juntas Provinciales, Junta Nacional y Consejo Ejecutivo" (Falange Nacional, 1954: 7). Lo anterior no sólo reafirma a los Centros como el núcleo básico de acción política sino también explicitan el carácter piramidal del Movimiento. Esto implica, y se puede ver en el listado de los delegados falangistas al Congreso Internacional Demócrata Cristiano del 55, un sustrato territorial en la composición de la élite partidaria. Menos de 50 de 323 delegados eran en ese momento dirigentes gremiales o universitarios (Reyes Vicuña, 1957: 84-95), lo que permite suponer que el resto de los delegados provenían de las estructuras territoriales (incluida la estructura nacional) y que para 1954, los Centros y Núcleos (hasta 10 militantes) llevaban la carga de la vida interna en cada una de sus reuniones ordinarias mensuales. En concordancia se distinguían sólo cuatro tipos de Departamentos Técnicos, Femenino, Sindical y Juvenil cuyos delegados participaban en la Junta Nacional con 15 cupos de cerca de 200. Los Departamentos, por demás, funcionaban dentro de cada Centro. La selección de los candidatos a regidores y diputados eran definidos también dentro de una estructura territorial, la Junta Provincial, lo que refuerza el sustrato territorial de la élite partidaria ${ }^{16}$.

Las elecciones de 1958 cambiarán este marco, notándose una fuerte participación de juventud universitaria (Boizard, 1963). Esta entrada alterará en la práctica las articulaciones incidentes dentro del ahora, partido Demócrata Cristiano. El papel de la Juventud Demócrata Cristiana y la Democracia Cristiana Universitaria en los quiebres de 1969 y 1971, además de establecer continuidad con la discusión sobre el acercamiento con los partidos de izquierda de 1941, no sólo demuestra que la fisura ideológica había sido ocultada pero no resuelta por la presidencialización de Frei, también evidencia que la incidencia en el partido se originaba en un espacio diferente al territorial y que los liderazgos que se desarrollarían con posterioridad a 1958 tendrían un sustrato más funcional que territorial.

De este cambio dan cuenta los estatutos del PDC de 1960, en los cuales se señala como obligaciones de todo militante demócrata cristiano, la participación en los "grupos y comuna" e incorporarse a organizaciones gremiales y sociales de distinto orden (PDC, 1960: 6). Si bien los estatutos del 60 consagran que la unidad básica del partido es la "Comuna", que reemplaza al "Centro", lo que reitera el carácter territorial, establece la constitución de "Grupos", organizados por a lo menos tres militantes y a lo más veinticinco, que tengan una actividad común (PDC, 1960:8). Las “Comunas", imagen de la división electoral vigente en ese momento, constituyen el espacio de cooperación de los “Grupos”, los cuales deben reunirse 
como mínimo una vez cada 15 días. Si se considera que los Centros y Núcleos falangistas debían reunirse, por lo menos semanalmente es posible suponer que la vida orgánica pasaba ahora a un segundo plano respecto al activismo político.

Como es posible ver, la vida partidaria se desarrolla en los "Grupos” y no en la "Comuna”. De hecho el límite de 25 personas escasamente será respetado, dando fortaleza a sus líderes. Los departamentos pasan de 4 a $12^{17}$, su incidencia en las estructuras superiores (Junta Provincial, Junta Nacional y Congreso Nacional) también se incrementan. Estos cambios en el funcionamiento orgánico dan más relevancia a la inserción funcional (o técnica según Gil), deviniendo de ésta la inserción territorial. Esto incide en la conformación de la élite partidaria que ahora conjunta una incidencia funcional y territorial.

Si bien la definición del militante no defiere mucho de la del falangista: "Son militantes democratacristianos las personas mayores de 16 años cuyos solicitudes de ingreso hayan sido aceptadas por el Consejo Comunal respectivo y que hayan prestado juramento de respetar y cumplir. los Principios y Estatutos del Partido Demócrata Cristiano” (PDC, 1960:5), el nuevo esquema tiene, por demás, un eje más inclinado hacia el activismo que hacia la contemplación doctrinaria. No sólo se cambia la figura adscriptiva en su formalidad (falangista por militante demócrata cristiano), ésta sufre una alteración de su contenido práctico. El dirigentes y el militante de base son activistas demócrata cristianos, es de ese aspecto del que da cuenta Lira Massi a un año de su llegada al gobierno "Cada soldado lleva en su mochila un bastón de Mariscal; cada demócrata cristiano lleva en su mochila un bombo" (Lira Massi, 1965: 5).

Esto es el resultado conjunto de la presidencialización del liderazgo personalizado de Frei, de la cual, en parte, la constitución del PDC también es, en algún modo, resorte (Boizard, 1963: 321). El triunfo presidencial de Frei se convierte en el objetivo que cementa el activismo y el partido. Lira Massi los ve como un club de fútbol, en el que "todos son cortados por la misma tijera. Son todos de una misma cuerda. Hechos a imagen y semejanza de Eduardo Frei, que es la estrella del equipo, el capitán y el entrenador; el Presidente del club, el que diseñó la camiseta y el dueño de la pelota” (Lira Massi, 1965: 6). Cuando habla Frei, "los demócrata cristianos se electrizan” (Ibid.: 8).

La clave del impacto de la presidencialización de Frei es que lo construye como una imaginario superior al partido. En la práctica esto se vio en la conformación de una orgánica ad hoc, que dio soporte técnico a su candidatura. Este rasgo, propio de los liderazgos personalizados, da el tono de la empresa de Frei, debía ser más que el partido. Tal es el sentido de la Patria Joven como operación política del liderazgo de Frei, no funciona sólo como un eslogan sino como una forma de movilización política. Frei apuesta en ello la constitución de las bases de un liderazgo renovador, deposita en esa nueva generación las fuerzas del destino. Como señalará en el 
célebre discurso de culminación de la Marcha de la Patria Joven: "Ustedes, jóvenes que han marchado, son mucho más que un partido, son mucho más que un hecho electoral. Son verdaderamente la Patria Joven que se ha puesto en marcha (...) Este movimiento y este hombre que está aquí para hablarles, representa la realización de las grandes tareas en el porvenir de la Patria (...) Yo creo que para realizar esta tarea ustedes tiene ser como los grandes guardianes. (...) La gente quiere honestidad en la dirección. Por eso mismo, ustedes jóvenes, mantengan su corazón limpio. Así servirán a su partido. Así servirán a su Patria” (Gazmuri, Arancibia y Góngora, 1996: 397- 399).

Frei incita, a los jóvenes reunidos para el cierre de su campaña, de la misma forma como alentó la separación del Falange Nacional del Partido Conservador, a cumplir con el porvenir de Chile. La recurrencia de ciertas imágenes: abrazar al país, patria, porvenir, no representan sólo lugares comunes discursivos, son el fondo los contenidos del programa freísta. En el cierre del discurso de 1964 Frei une el destino de esos jóvenes, y el suyo mismo, con los destinos de la Patria, pues los asistentes a ese acto son más que los demócrata cristianos o los freístas. Ante un cúmulo de banderas chilenas, democristianas y freístas señala: “¿no ves las banderas?. Son los mismos, los del año 1810, los de 1879, los de 1891. ¡Son la Patria! (...) ¡Son la Patria, gracias a Dios!” (Gazmuri, Arancibia y Góngora, 1996: 402). En estos momentos, el liderazgo de Frei va a acaballo sobre un optimismo desmesurado respecto a la campaña de 1964, lo que incluye visos de mesianismo (Gazmuri, 2000b: 511) que nunca estuvieron ausentes de la lírica del candidato.

Frei se trastoca desde un líder partidario hacia un líder carismático, pero la distancia que hay entre este hecho y el tipo puro definido por Weber es la débil institucionalización de este liderazgo. La operación freísta no logra cooptar con un discurso unitario las tensiones ideológicas que venían acentuándose en la falange. Ya en el Congreso Nacional de 1959, Frei había debido mediar entre las posturas "purista", del camino propio, vanguardista, nacional y popular, defendida por Jaime Castillo Velasco, y la postura "popular", de apertura hacia la izquierda, defendida por Rafael Agustín Gumucio, Alberto Jeréz y Julio Silva Solar. La reaparición de esta tensión, que data desde 1946 (Greyson, 1968: 235), obliga y permite a Frei ordenar el partido bajo su figura y mediante una postura intermedia, defendida por él mismo, Patricio Aylwin, Tomás Pablo y Juan de Dios Carmona (Gazmuri, 2000b: 508). La mediación de las dos posturas contrarias muestra ser efectiva sólo momentáneamente. Su error radica en que la postura Frei evita el enfrentamiento pero no supera sus causas, pero el hecho de haber articulado la postura finalmente ganadora lo coloca como el gran vencedor de ese congreso y lanza su candidatura presidencial con un partido cohesionado en su figura (Grayson, 1968: 316).

Las actuaciones públicas de Frei van incrementando la estatura presidencial de su figura y con ello el entusiasmo de un creciente freísmo. Para las elecciones municipales de 1960, la Democracia Cristiana presentó 910 
candidatos, cuyas campañas fueron acompañadas por visitas de Frei en casi todo el país. El 13,9\% obtenido nacionalmente situó al PDC como la tercera fuerza electoral y a Frei como un liderazgo presidencial propiamente tal, lo cual fue acompañado por victorias en elecciones de federaciones estudiantiles, sindicatos y confederaciones y su elección como presidente del PDC en 1961.

Las campañas parlamentarias de 1961 también contaron con su apoyo en terreno, lo que valió un $15,4 \%$ de los votos nacionales y una fuerza parlamentaria de 23 diputados y 3 senadores (Gazmuri, 2000b: 518). Pero esto no era suficiente para asegurar el triunfo en 1963. Como lo señaló Frei en el Consejo Plenario Nacional de abril de 1961, el partido organizativamente no estaba a la altura de la empresa y del fervor que se había creado en el país. Tanto la organización del partido era “mala” como los militantes no aportaban los fondos necesarios, lo que fue ratificado por Tomás Reyes (Ibid.: 520).

Fondos y organización no son problemas menores en un contexto así, la naturaleza misma de este reproche proviene de un liderazgo que su partido no da el ancho de las circunstancias. Este no es un reproche a sí mismo en tanto demiurgo de su partido, y en realidad no lo era, Frei es un símbolo de la Democracia Cristiana, pero no es sólo sobre sus hombros donde ha recaído el trabajo de su formación. Eso le permite a Frei jugar con las distancias. En este caso, el partido debe a ponerse a tono con su empresa. Esto reflotó la discusión sobre el sentido de las alianzas, lo que denota la importancia de este mecanismo para las élites democristianas. Pero el problema fue resuelto desde el mismo liderazgo: los fondos provinieron de fuentes que los dirigentes de esa época dicen todavía desconocer, lo que la buena fe nos lleva a pensar de que fueron gestionados por el propio Frei en Estados Unidos, Alemania e Italia durante su gira en 1962 (Gazmuri, 2000b: 541-543). En el mismo sentido, la necesidad de apoyar a Frei para evitar el triunfo de Allende motivó también el apoyo económico (no institucional) de la derecha a su candidatura (Greyson, 1968: 395)

El déficit organizativo señalado por Frei, parece no ser apreciado por Greyson, quien señala que para 1963, "El PDC dedicaba tremenda energía y gastos a la organización y publicidad durante este periodo. Los locales demócrata cristianos se levantaban incluso en los más remotos villorrios, se distribuían manuales organizativos, se realizaban especiales esfuerzos por reclutar estudiantes, trabajadores, profesionales, mujeres y campesino, en las organizaciones menores de partido. Los social cristianos nunca cesaron de hablar en términos de su “misión”, su “cruzada”, su “ola” (Greyson, 1968: 344). Para 1963, un nuevo estatuto entraría en vigencia cuya principal innovación respecto del estatuto de 1960 es la inclusión de la pre militancia, de duración de un año, y la subida en el mínimo de edad para ser aceptado como militante de 16 a 18 años (Ibid.: 377 ss.). Considerando las criticas de Frei a la debilidad organizativa del PDC en 1961, es significativo que los nuevos estatutos no dieran cuenta de un cambio en la estructura orgánica, esto permite suponer que Frei no apuntaba necesaria- 
mente a ese aspecto del partido sino al esquema de organización de su presidencialización, allanando el camino a la articulación de una orgánica ad hoc que se mostrará con mayor fuerza durante su periodo presidencial.

Todos los elementos señalados fueron puestos en juego en las elecciones municipales de 1963, pues eran la antesala directa de la presidenciales del año siguiente. Sus resultados colocaron al PDC como el partido más votado con un 22,7\%, seguido de cerca por el partido radical con un 21,\%. Sin embargo, la alianza de izquierda, que ya había elegido como su candidato a Salvador Allende, acaparaba en su conjunto el 29,5\% de los votos, mientras los partidos de derecha (Conservador Unido y Liberal) juntaban el 24,6\%). Estos resultados no sólo demostraron la competitividad potencial del candidato DC, sino también el fuerte incremento de los votos de izquierda.

El 47\% que habían obtenido el Frente Democrático (integrando al PDC) y la elección del radical Julio Durán Neumann como candidato presidencial adolecían, justamente, de la venia del PDC, que al nominar a Frei llevó a un escenario en que, para frenar el triunfo de la izquierda, o una de las candidaturas se retiraba o se apoyaba a quien se viera más claramente como vencedor (Correa Sutil, 2004). La elección complementaria de Curicó en marzo de 1964, provocó esta definición. Auspiciada como un plebiscito por el candidato radical la derrota de la alianza de derecha a manos de la izquierda, costó la renuncia momentánea de Durán a la carrera presidencial, la disolución de la alianza de derecha y la inclinación final de la balanza a favor de Frei.

\section{Conclusión. Perspectivas sobre las formas de acción colectiva pre elíticas}

En el texto precedente se ha querido exponer el caso de una organización política donde es posible distinguir, con cierta claridad, el funcionamiento de dos tipos de acciones colectivas: operaciones doctrinarias y pragmáticas; y los efectos del desarrollo de este tipo de acciones en la forma orgánica del partido y las figuras adscriptivas asociadas al mismo.

El análisis de la Falange Nacional evidencia que nociones interaccionales que se han venido trabajando con posterioridad a los años 70s, son aplicables a partidos de la fase anterior, los que se suponía correspondía a modelos menos fragmentados organizacionalmente y más unívocos en términos de intereses y objetivos. En este caso, la presencia de más de un tipo de operación política funcionando en pos de objetivos discrecionales y estableciendo competencia, permite, por lo menos, cuestionar el supuesto del grupo homogéneo y deja en posición de tiro el supuesto del partido de alta institucionalización, pues las desagregaciones de sectores ocurren en el periodo inmediatamente posterior al recién analizado y se explican, en parte, por fenómenos como los ya mencionados. 
También es necesario reconsiderar aquellas explicaciones que reducen el análisis de la acción política a la maximización del voto. Tal como lo hemos visto en el caso anterior, y coincidente con los resultados de Gunther sobre la España post franquista, no todas las decisiones de los liderazgos partidarios, y por ende de los partidos, se orientan con exclusividad a la maximización del voto, pudiendo ir incluso en la dirección contraria (Gunther, 1989). En el mismo sentido, no todos los movimientos internos tienen como máxima la corroboración electoral y la ampliación del grupo parlamentario. En el caso de los dos tipos de operaciones vistas, la operación doctrinaria busca su vigencia en procesos de reafirmación interna e incidencia externa, pudiendo pervivir un periodo de tiempo significativo en esta estrategia. Mientras que operaciones pragmáticas sumarán a estos aspectos el desempeño electoral.

Las constantes variaciones en el funcionamiento de los partidos, las divergencias funcionales entre estructuras y las también permanentes situaciones de contradicción y antagonía entre partes funcionales de una misma organización y/o con elementos organizacionales ajenos a estos, sugiere no sólo una mayor inestabilidad natural que la supuesta tradicionalmente. En tal sentido se proponen dos explicaciones a la variación orgánica detectada: 1) Las variaciones se dan por la presencia de operaciones de determinada naturaleza, es decir por movimientos de recursos políticos caracterizables y diferenciables, lo que puede orientar en la comprensión de la génesis de la divergencia funcional. Y, 2), las variaciones son afectadas por la preeminencia de un tipo de operación sobre otra, es lo que ocurriría cuando lo apreciable son variaciones de baja intensidad.

Esto implica no considerar a los partidos como organizaciones finales o terminadas sino como en constante proceso de adecuación a la naturaleza y efectividad de sus operaciones internas, lo cual, puede o no estar en coherencia con la estructura orgánica declarada oficialmente en sus estatutos. Aún cuando son un importante registro que da cuenta de la forma cada partido previo estructuralmente su estrategia de inserción en la geografía electoral del país, es difícil suponer que los partidos funcionan en realidad mediante esas estructuras declaradas. Son numerosos los relatos y entrevistas que dan cuenta de cómo reuniones no concebidas estatutariamente resultan ser más decisivas y numerosas que las patadas en los reglamentos. Esto tampoco implica su extremo, que sería suponer que los partidos funcionan como quieren y como pueden.

Al igual como se ha experimentado en los últimos 20 años respecto a los liderazgos presidencializados (Vergara Vidal, 2011a), en el periodo caracterizado por la operación freísta fue posible apreciar varios de los elementos de los que darían cuenta posteriormente autores como Panebianco, Puhle, Wolinetz, etc. Incluso en un caso prototipo como la Falange Nacional y la Democracia Cristiana temprana no encontramos la fortaleza burocrática que el discurso común insiste en ubicar en ese periodo. ¿Contradice esto la tesis de la alta institucionalización? Lo cierto es que no, pero de lo cual resulta una paradoja: existe una alto nivel de institucionalización y eso 
es posible ver en los congresos, planes orgánicos y relatos sobre el funcionamiento de la Falange temprana, pero una vez desplegado la operación freísta son los requerimientos electorales de ésta los que alteran el funcionamiento orgánico y desestructura la burocracia partidaria a favor de una estructuración de una burocracia electoral. No hay ausencia o vacíos de instituciones, son alteradas las naturalezas de estos espacios y surgen, con la primera campaña presidencial de Frei, orgánicas ad hoc que permanecerán operando el freísmo incluso desde altas (e indeterminadas) esferas de gobierno.

Todo lo anterior implica que es necesario revisar ciertas percepciones sobre los partidos políticos chilenos anteriores a 1973, en gran parte subsidiarias del análisis de tipologías de organizaciones desarrollado por Duverger (1951), LaPalombara (1966), Panebianco (1982), entre otros. Esa importante batería conceptual puede ser hoy complementada con aportes de la teoría de la acción colectiva, de la acción racional y los enfoques agregativos, quienes pueden ofrecer instrumentos útiles para el análisis de fenómenos moleculares y sincrónicos en las organizaciones políticas actuales y anteriores. Lo importante es superar las visiones que reducen el análisis político a una perspectiva diacrónica y al análisis de las grandes organizaciones formales.

En tal sentido, el presente trabajo no buscó determinar lo contrario pero los resultados de la investigación bibliográfica y documental realizada arrojan que fenómenos como los descritos por la literatura reciente ya se pueden encontrar en los partidos políticos de la década del 1930. En este texto en específico ahondamos el caso de la Falange Nacional pero es posible afirmar que situaciones similares se desarrollaban en los otros partidos de la época. Es más, las lógicas de funcionamiento descritas pueden ser extrapoladas hasta loas partidos actuales, tal como hemos tratado de demostrar en trabajos anteriores. Esto implica que los modelos tipológicos de partidos, y el análisis sustentado en ellos, deben ser revisados y complementados con perspectivas que permitan distinguir y apreciar los elementos, asociaciones e interacciones que se activan dentro de una organización política cuando esta se encuentra en funcionamiento. 


\section{Notas}

${ }^{1}$ El presente trabajo es parte de la investigación doctoral "La operación política. Configuraciones colectivas en los liderazgos políticos chilenos 1989-2012”, en proceso de realización por el autor.

${ }^{2}$ Cruz-Coque ingresaría a las filas del Partido Conservador en 1920, fue candidato a la presidencia de la república por dicho partido en 1946, siendo apoyado por la Falange Nacional

${ }^{3}$ Como señala Gumucio: “Cuando fui elegido presidente del partido, me encontré con que éste no tenía juventud. Los jóvenes que actuaban en la Asamblea de Propaganda eran poquísimos. Los alumnos universitarios eran apolíticos y tenían distanciamiento del Partido Conservador. Se logró reunir un grupo formado , entre otros, por Bernardo Leighton, Manuel Garretón, Ignacio Palma; Eduardo Frei y Radomiro Tomic, a quienes en una comida en mi casa puse en contacto con los Jefes Conservadores don Héctor Rodríguez de la Sotta y don Horacio Walker” (Silva Bascuñán, 1949: 41; Gazmuri, 2000: 202). Por demás, algo de la experiencia de la movilización estudiantil contra Ibáñez, liderada en la Universidad Católica por Leighton y Rafael Agustín Gumucio y el activismo social cristiano había sembrado en estos anecistas la necesidad de pasar a la arena política (Greyson, 1964: 106). Fueron justamente ellos los primeros en ingresar a la Asamblea de Propaganda Conservadora en 1933 (Gazmuri, 2000: 204), bajo la idea de obtener una plataforma para el desarrollo de reformas sociales (Greyson, 1968: 109).

${ }^{4}$ En la Convención Nacional de octubre de 1935 se establece la formación del Movimiento Nacional de la Juventud Conservadora, los estatutos que le dan forma señalan la creación de "se crea una organización general de la Juventud Conservadora, dependiente de la Junta Ejecutiva del Partido Conservador, cuyo objeto es la formación de los jóvenes que a ella pertenezcan y la difusión de los ideales del Partido Conservador, por medio del estudio, la acción y la propaganda en centro organizados”. El documento señala que, “en lo demás, la acción política de los jóvenes deberá efectuarse dentro de los organismo oficiales del Partido Conservador” (Silva Bascuñán, 2008: 47). Se señala además que “pertenecerán a la juventud conservadora, las personas que aceptando los principios y programas del partido conservador cumplan con los requisitos siguientes: haber suscrito los registros del correspondiente organismo de la Juventud Conservadora; tener 16 años de edad y no más de 35; los mayores de 21 años deberán estar inscritos en los Registros Electorales” (Ibid.) De esta manera el texto consagra que no es requisito para formar parte de este órgano la pertenencia al Partido Conservador sino solamente compartir sus principios y programas.

${ }^{5}$ Lircay, 14 de noviembre de 1936.

${ }^{6}$ Mientras Boizard señala como autor a Garretón Walker, luego de su viaje en 1934 a Europa, aspecto corroborado por Silva Bascuñán (2008) Ignacio Palma se atribuye el hecho en una entrevista a Greyson (Greyson, 1968: 162) lo que refrendado por Jorge Rogers (Gazmuri, 2000: 207)

7 “Ellos fueron: Alberto Bahamondes (Antofagasta), Manuel José Irarrázabal (Coquimbo), Fernando Durán (Valparaíso), Pablo Larraín (Santiago), Guillermo Echeñique (San Vicente) y Ricardo Boizard (Lontué)” (Greyson, 1968: 142)

${ }^{8}$ Punto 26. En “Los 27 puntos de la Falange Española de las JONS”. Madrid. 1934 
${ }^{9}$ Punto XXIV. En “Los 24 puntos fundamentales de la Falange Nacional”. Greyson, 473481)

${ }^{10}$ Silva Bascuñán sostiene que, para 1938, “era entonces Manuel Garretón el más rígido, dogmático, consistente y completo expositor del ideario falangista y quien más le dio novedad, originalidad y personalidad a la forma de su exposición, aún cuando quienes no participaban de su criterio le tacharan oscuridad en la expresión y lo calificaran como incomprensible” (Silva Bascuñán, 1949: 144)

${ }^{11}$ En este sentido no es menor el cierre del discurso con que en 1946 Pedro Rodríguez J., entonces presidente de la Falange conmemora el 11avo aniversario de la agrupación: "Juventud chilena adelante!” (Rodríguez J, 1946), frase utilizada desde las circulares de 1935, ni su inicio: "Muchas veces he dado gracias a Dios, desde lo más profundo de mi alma, por haberme incorporado a una generación ante la cual se presenta el gigantesco espectáculo de una etapa histórica que termina y una que nace”(Ibid.), este tipo de alocuciones serán frecuentes en la élite falangista-democristiana.

${ }^{12}$ Leighton (1935), Rafael Agustín Gumucio (1940 y 1946), Eduardo Frei (1945 y 1954) y Radomiro Tomic (1954) ocuparon cargos ministeriales. Manuel A. Garretón Walker (1945) fue embajador en Turquía; Jorge Rogers (CORFO)

${ }^{13}$ Recién culminado el periodo de Frei Montalva como presidente de la Falange Nacional

${ }^{14}$ El listado también nos permite sacar otras conclusiones. Están presentes algunos nombres que acompañarán la desagregación de la Juventud Demócrata Cristiana en 1969 para formar el Movimiento de Acción Popular Unitaria (MAPU): Vicente Sota, Alberto Jerez, Julio Silva Solar, Rafael Agustín Gumucio, entre otros. Salvo Vicente Sota, estos mismos nombres darán fundación a la Izquierda Cristiana en 1971, una segunda desagregación de la DC: Jaime Concha, Pedro Videla, Bosco Parra, Pedro Felipe Ramírez, Luis Maira, Osvaldo Giannini, Alberto Jerez, Julio Silva Solar; Jacques Chonchol, Rafael Agustín Gumucio.

${ }^{15}$ Tanto el programa "nacional y popular" como el uso de los dedos en "V" guardan una similitud estricta con el peronismo argentino.

${ }^{16}$ Angell sostiene que para 1964, la influencia del departamento sindical era débil y que está área de acción carecía de asistencia económica y doctrinal. (Angell, 1974: 194)

${ }^{17}$ Los departamentos son: Sindical, Juventud, Campesinos, Pobladores, Cooperativas, Capacitación Doctrinaria, Técnico, Electoral, Municipal, Acción Social, Finanzas, Internacional y otros que pudiesen conformarse posteriormente (PDC, 1960: 9) 


\section{Bibliografía}

Angell, Alan (1974), Partidos políticos y movimiento obrero en Chile. De los orígenes hasta el triunfo de la Unidad Popular. Ediciones Era, México.

Boizard, Ricardo (1931), Hacia el ideal político de una juventud. Conferencia dictada en la Asamblea Conservadora. Nascimento, Santiago.

Ídem (1963), La Democracia Cristiana en Chile (Un mundo que nace entre dos guerras). Editorial Orbe, Santiago.

Castillo Velasco, Jaime (1968), Las fuentes de la democracia cristiana. Editorial del Pacífico, Santiago.

Ídem (1971), Individualismo, colectivismo, comunitarismo. Instituto de Estudios Políticos, Santiago.

Cash Molina, Jorge (1986), Bosquejo de una historia. Falange Nacional 1935-1957. Imprenta Pucara, Santiago.

Duverger, Maurice [1951] (2002), Los partidos políticos. Fondo de Cultura Económica, México.

Edwards Vives, Alberto y Frei Montalva, Eduardo. (1949), Historia de los partidos políticos chilenos. Editorial del Pacífico, Santiago.

Falange Nacional (1940) Puntos fundamentales del programa de la Falange Nacional; Estatutos de la Falange Nacional; Primer Congreso Provincial de Santiago. Imprenta Gutemberg, Santiago.

Ídem (1941), Segundo Congreso Nacional: 19 y 20 de Julio de 1941: Bases, Reglamentos. Imprenta Gutemberg, Santiago.

Ídem (1943), La Falange y la política internacional de Chile: antecedentes y documentos. Departamento Nacional de Cultura y Propaganda, Santiago

Ídem (1954), Declaración de principios y estatutos. Del Pacífico, Santiago.

Fariña, Carmen. (1987), "Notas sobre el pensamiento corporativo en la Juventud Conservadora a través del periódico “Lircay”. 1934-1940”. En Revista de Ciencia Política. Vol. IX. Nº 1. 1987, Santiago.

Frei Montalva, Eduardo (1937), Ideas sobre la reconstrucción del Hombre. Lircay, Santiago.

Friedmann, Reinhard (1988), 1964-1988. La política chilena de la A a la Z. Melquíades, Santiago. 
Garretón Walker, Manuel Antonio (1937), Nuestro concepto de la política. Lircay, Santiago.

Gazmuri, Cristián (2000), Eduardo Frei Montalva y su época. Tomo I. Aguilar, Santiago

Ídem (2000b), Eduardo Frei Montalva y su época. Tomo I. Aguilar, Santiago.

Gazmuri, Cristián; Arancibia, Patricia y Góngora, Álvaro (1996). Eduardo Frei Montalva (1911-1982), Fondo de Cultura Económica. Santiago,

Gil, Federico (1969), El sistema político de Chile. Editorial Andrés Bello, Santiago.

Greyson, George (1968), El Partido Demócrata Cristiano chileno. Editorial Francisco de Aguirre, Buenos Aires.

Guilisasti, Sergio (1964), Partidos político chilenos. Nascimento, Santiago.

Gunther, Richard (1989), "Electoral Laws, Party System, and Elites: The Case of Spain”. En The American Political Science Review Vol. 83, No. 3 (Sep., 1989), pp. 835-858

Hawkins, Kirk (2010), “Sembrando ideas. Explicación de los orígenes de los partidos democratacristiano en Latinoamérica”. En Mainwaring, Scott y Scully, Timothy (Eds.) (2010). La Democracia Cristiana en América Latina. Conflictos y competencia electoral. Fondo de Cultura Económica. Pp. 118-170, México.

Hirschman, Albert (1982), Shifting involvements: private interest and public action. Princeton University Press, New York.

Huneeus, Carlos (2003), “Un partido con un alto grado de institucionalización. EL PDC en Chile”. Stanford Universyty Press, Stanford.

Ídem (2010), “Un partido político muy institucionalizado: la democracia cristiana en Chile”. En Mainwaring, Scott y Scully, Timothy (20109. La Democracia Cristiana en América Latina. Conflictos y competencia electoral. Fondo de Cultura Económica, México.

LaPalombara, Joseph y Weiner, Myron (comps.) (1966), Political Parties and Political Development. Princeton University Press, New Jersey.

Lira Massi, Eugenio (1965), Frei y los desconocidos de ahora. Ediciones Punto Final, Santiago. 
Ídem (1968), La cueva del Senado y los 45 senadores. TE-ELE Ediciones, Santiago.

Michels, Robert [1911] (2003), Los partidos políticos I. Un estudio sociológico de las tendencias oligárquicas de la democracia moderna. Amorrortu Editores, Buenos Aires.

Mosca, Gaetano [1986] (2006), La clase política. Fondo de Cultura Económica, México.

Olson, Mancur (1992), La lógica de la Acción Colectiva. Bienes Públicos y la Teoría de Grupos. Editorial Limusa, México.

Ostrogorski, Moisei (1903). La democracia y los partidos políticos. Trotta, Madrid.

Palma Vicuña, Ignacio (1937), Elementos chilenos para un orden nuevo. Lircay, Santiago.

Panebianco, Angelo (1982), Modelos de Partidos. Alianza Editorial, Madrid.

Pareto, Wilfredo (1980), Forma y equilibrio sociales. Alianza: Editorial, Madrid.

Partido Demócrata Cristiano (1960), Estatutos del Partido Demócrata Cristiano, Santiago.

Ídem (1962), El A-B-C de la Democracia Cristiana. Concepción: Instituto de Estudios Políticos del PDC de Concepción

Ídem (1970), Fundamentos de la Democracia Cristiana. Manual de Adoctrinamiento para militantes y simpatizantes. Departamento Nacional de Capacitación Doctrinaria - PDC. Mayo de 1970, Santiago.

Ídem [1973] 1987,. El pensamiento de la Democracia Cristiana. Taller Emmanuel Mounier, Santiago.

Ídem (1993), Doctrina del PDC. Modulo I. Identidad doctrinaria y política del PDC. Serie Difusión IV Congreso. Instituto Chileno de Estudios Humanísticos, Santiago.

Pereira, Teresa (1994), El Partido Conservador: 1930-1965, ideas, figuras y actitudes. Editorial Universitaria, Santiago.

Portales, Felipe (2006), Los mitos de la democracia chilena. Desde la conquista hasta 1925. Catalonia, Santiago.

Reyes Vicuña, Tomás (Comp.) (1957), Congresos Internacional Demó- 
crata Cristianos. Editorial del Pacífico, Santiago.

Rodríguez, Pedro J. (1946), El grave momento político de Chile y la Falange Nacional. Falange Nacional, Santiago.

Sartori, Giovanni (1988) Teoría de la democracia. 1. El debate contemporáneo. Alianza Editorial, Madrid.

Sepúlveda Almarza, Alberto (1996), Los años de la patria joven: la política chilena entre 1938-1970. ChileAmerica CESOC, Santiago.

Silva Bascuñán, Alejandro (1949), Una experiencia social cristiana. Editorial del Pacífico, Santiago.

Ídem (2008), Una experiencia social cristiana (Formación de la Falange). CESOC, Santiago.

Tarrow, Sidney [1998] (2009), El poder en movimiento. Los movimientos sociales , la acción colectiva y la política. Madrid: Alianza Editorial

Tomic Romero, Radomiro. (1945), Fundamentos cristianos para una nueva política en Chile. Falange Nacional, Santiago.

Urzúa Valenzuela, German (1968), Los partidos políticos chilenos. Las fuerzas políticas. Editorial Jurídica de Chile.2, Santiago.

Vergara Vidal, Jorge (2011 a), Liderazgos persistentes en la oposición de derecha en Chile. 1988-2009. Tesis de Magíster en Ciencias Sociales. Universidad de Chile, Santiago.

Ídem (2011b), “La desagregación política. Reflexiones sobre la actuación de las élites partidarias en las crisis de los partidos políticos”. En Revista Polis 30. Universidad Bolivariana, Santiago.

Ídem (2012), "Elites partidarias. Reflexiones sobre las formas operatorias del liderazgo político”. En Revista de Sociología Número 26 (2012) (en prensa). Universidad de Chile, Santiago.

Weber, Max [1922] (2005), Economía y Sociedad. Esbozo de Sociología Comprensiva. Fondo de Cultura Económica, México.

Recibido: 15.06 .2012

Aceptado: 25.07.2012 